Quebec Cooperative Study of

Friedreich's Ataxia

\title{
Lipoamide Dehydrogenase Regulation in Rat Brain
}

\author{
T. T. NGO AND A. BARBEAU
}

SUMMARY: The Pyruvate dehydrogenase multienzyme complex $(P D H C)$ purified from rat brain is phosphorylated in the presence of low concentrations of ATP and $\mathrm{MgCl}$. The phosphorylated $P D H C$ is incapable of catalyzing the oxidative decarboxylation of pyruvate. In the presence of high concentrations (10 $\mathrm{mM}$ ) of $\mathrm{MgCl}$, the phosphorylated (inactive) PDHC is converted back to the dephospho-form of PDHC which is catalytically active.

RÉSUMÉ: Le complexe multienzymatique de la pyruvate dehydrogenase (PDHC) purifié du cerveau de rat est phosphorylé en présence de basses concentrations d'ATP et de $\mathrm{MgCl}_{2}$. Le PDHC phosphorylé est incapable de cataliser la décarboxylation oxydative du pyruvate. En présence de fortes concentrations $(10 \mathrm{mM})$ de $\mathrm{MgCl}$, le PDHC phosphorylé (inactif) est transformé en sa forme déphosphorylée qui est catalytiquement active.

La composante dehydrolipoyl dehyd-
The dihydrolipoyl dehydrogenase (LAD) component, E3, of PDHC is inactivated by pyridoxal phosphate (PLP) and the PLP-inactivated LAD can be reactivated by an amino acid, taurine. These results indicate the reversible formation of Schiff base between PLP and $L A D$. They also provide clear evidence for the involvement of $L A D\left(E_{3}\right)$ in the previously reported inactivation of $P D H C$ by PLP.

rogenase (lipoamide dehydrogenase, $L A D), E_{3}$, du PDHC est inactivée parle pyridoxal phosphate $(P L P)$. Le $L A D$-inactivé par le PLP peut ensuite être réactivé par un acide aminé, la taurine. Ces résultats indiquent qu'il existe une formation réversible de "Schiff base" entre le PLP et le LAD. Ils suppléent également un argument important en faveur de limplication di $L A D\left(E_{3}\right)$ dans l'inactivation du PDHC par le PLP, inactivation que nous avions préalablement rapporté.
From the Department of Neurobiology, Clinical Research Institute of Montreal.

Reprint request for the complete supplement on Friedreich's ataxia (Phase Two, Part One) to: Dr. André Barbeau, Clinical Research Institute of Montreal, 110 Pine Avenue West, Montreal, Quebec, Canada H2W IR7.

\section{INTRODUCTION}

The conversion of pyruvate to acetyl-coenzyme A, catalyzed by the pyruvate dehydrogenase multienzyme complex (PDHC), is an important step in cellular energy metabolism. It is the link connecting the glycolytic pathway to the energy yielding tricarboxylic acid cycle. It is thus an important crossroad leading to the formation of the building blocks for fatty acids and amino acids biosynthesis. Mammalian PDHC has been shown to exist in two interconvertible molecular forms. Phosphorylation by ATP results in an inactive phosphorylated form of PDHC; it can be activated by high magnesium concentration with concomittant dephosphorylation (Reed, 1974; Hucho, 1975; Denton et al., 1975).

The pyruvate dehydrogenase multienzyme complex from nervous tissue has not often been studied (Blass and Lewis, 1973; Siess et al., 1971). Using purified PDHC from rat brain, Ngo and Barbeau (1978) have performed a detailed study of the steady state kinetics. In view of the possible involvement of this enzyme in Friedreich's ataxia (Barbeau et al., 1976; Blass et al., 1976), we have investigated its regulatory properties in rat brain. This paper details the enzymatic phosphorylation and dephosphorylation, the non-enzymatic inactivation by pyridoxal phosphate and the reversal of pyridoxal phosphate inactivated PDHC by taurine. An attempt has been made to locate the site and mode of action of pyridoxal phosphate on PDHC.

\section{MATERIALS AND METHODS} Animals

Male Charles River rats weighing $250 \mathrm{~g}$ were used for this study. The animals were maintained in our ani- 
mal quarters for at least 3 days prior to use and during this time had unlimited access to food and water.

\section{Chemicals}

Pyruvate, $\beta$-nicotinamide adenine dinucleotide (NAD), reduced nicotinamide adenine dinucleotide (NADH), adenosine triphosphate (ATP), thiamine pyrophosphate (TPP), dithiothreitol (DTT), pyridoxal-5'-phosphate (PLP), taurine and lipoamide were purchased from Sigma Chemical Co. Coenzyme A (CoASH) and acetyl CoA were purchased from P-L Biochemicals.

Purification of rat brain pyruvate dehydrogenase multienzyme complex

The rats were killed by a sharp blow to the back of the neck and the brain quickly removed and put on a precooled glass dish. The brains of 20 rats weighing about $40 \mathrm{~g}$ were homogenized with $80 \mathrm{ml}$ of $50 \mathrm{mM}$ sodium phosphate buffer (SPB), $\mathrm{pH}$ 7.5 containing $1 \mathrm{mM} \mathrm{MgCl} 2$ and 5 $\mathrm{mM}$ DTT in a glass-teflon homogenizer. After adding another $60 \mathrm{ml}$ of SPB, the homogenate was stirred for $2 \mathrm{~min}$ and followed by centrifugation at $1000 \mathrm{Xg}$ at $4^{\circ} \mathrm{C}$ for $10 \mathrm{~min}$ in a Beckman J-21B centrifuge, and the supernatant was saved. Twenty $\mathrm{ml}$ of SPB was added to the pellet, which was homogenized as before, the homogenate was centrifuged at 1000 $\mathrm{Xg}$ at $4^{\circ} \mathrm{C}$ for $10 \mathrm{~min}$. The supernatants from the previous steps were combined and centrifuged at 30,000 $\mathrm{X} \mathrm{g}$ for $10 \mathrm{~min}$, the supernatant of this fraction discarded. The pellet was washed with $10 \mathrm{ml}$ of SPB and dispersed with the aid of a glass rod, the suspension obtained centrifuged at $30,000 \mathrm{Xg}$ for $10 \mathrm{~min}$ at $4^{\circ} \mathrm{C}$. The supernatant was discarded and $10 \mathrm{ml}$ of SPB was added to the pellet which was homogenized. This homogenate was then sonicated with a sonic 300 Dismembranator for $15 \mathrm{sec}$ at $4^{\circ} \mathrm{C}$. The sonicated solution was centrifuged at $30,000 \times \mathrm{g}$ for $5 \mathrm{~min}$ and the supernatant saved. The pellet was again homogenized with $10 \mathrm{ml}$ of SPB, sonicated and centrifuged as above. This process of homogenization, sonication and centrifugation was repeated 4 times. The resulting supernatants were pooled and the $\mathrm{pH}$ of the solution adjusted slowly to 6.4 with $1 \%$ acetic acid solution at $4^{\circ} \mathrm{C}$. The $\mathrm{pH} 6.4$ solution was centrifuged at $18,000 \times \mathrm{g}$. One percent acetic acid was added to the supernatant until the $\mathrm{pH}$ of the solution was 5.6 , and this $\mathrm{pH} 5.6$ solution was centrigued at $18,000 \mathrm{Xg}$ for $15 \mathrm{~min}$. The precipitate was dissolved in $5 \mathrm{ml}$ of SPB and dialyzed overnight at $4^{\circ} \mathrm{C}$ against $4,000 \mathrm{ml}$ of SPB. The dialysate was clarified by centrifugation at $18,000 \mathrm{Xg}$ for $15 \mathrm{~min}$ at $4^{\circ} \mathrm{C}$ and the clear supernatant was used as the enzyme source. The specific activity of the enzyme was 1.6 $\mathrm{U} / \mathrm{mg}$. When not in use, the enzyme was stored in $20 \mathrm{mM}$ sodium phosphate buffer, $\mathrm{pH} 7.5$, containing $40 \%$ glycerol and $5 \mathrm{mM}$ DTT and kept at $-20^{\circ} \mathrm{C}$. Under this condition the enzyme was stable for at least 6 months without loss of activity.

\section{Kinetic procedures}

The initial rate of the PDHC catalyzed reactions was measured by an increase in absorbance at $\mathbf{3 4 0}$ $\mathrm{nm}$, due to the formation of NADH. The reaction was carried out in a Beckman Acta M VI recording spectrophotometer thermostatted at $30^{\circ} \mathrm{C}$. The assay solution $(1 \mathrm{ml})$ contained $50 \mu$ moles sodium phosphate, pH 7.5, $0.5 \mu$ mole TPP, 1 $\mu$ mole $\mathrm{MgCl}_{2}, 5 \mu$ moles, DTT, 8 $\mu$ moles pyruvate, $5 \mu$ moles $\mathrm{CoA}$ and $1 \mu$ mole NAD. After temperature equilibration, the reaction was initiated by the addition of 75-200 $\mu \mathrm{g}$ enzyme.

The measurement of the activity of pyruvate dehydrogenase kinase (PDHK) was based on the initial rate of inactivation of $\mathrm{PDHC}$ in presence of ATP and bound kinase. Phosphorylation of $\mathrm{PDHC}$ was carried out at $30^{\circ} \mathrm{C}$ in a solution $(1.0 \mathrm{ml})$ containing $4 \mathrm{mg}$ of PDHC, $1 \mu$ mole $\mathrm{MgCl}_{2}, 5 \mu$ moles, $50 \mu$ moles sodium phosphate, $\mathrm{pH} 7.5$ and varying amounts of ATP as required. ATP was omitted from the control. Phosphorylation was initiated by the addition of ATP. An aliquot of $25 \mu \mathrm{l}$ was withdrawn at various time intervals after the addition of ATP and diluted 40 times with the solution used for the assay of PDHC, the absorbance at $340 \mathrm{~nm}$ was immediately studied. The difference in the change of absorbance per minute between the control and the test samples is a measure of PDHK activity. This assay method was developed by Linn et al. (1972).

The activity of pyruvate dehydrogenase phosphatase (PDHP) was followed by the reactivation of inactive PDHC (phosphorylated) in presence of $10 \mathrm{mM} \mathrm{MgCl} 2$ and bound PDHP. ATP-inactivated PDHC (4-5 $\mathrm{mg}$ ) was incubated at $30^{\circ} \mathrm{C}$ in a solution $(1.0 \mathrm{ml})$ containing $5 \mu$ moles DTT, $50 \mu$ moles sodium phosphate, pH 7.5 and $10 \mu$ moles $\mathrm{MgCl}_{2}$. The reactivation was initiated by the addition of $10 \mathrm{mM} \mathrm{MgCl}_{2}$ and $25 \mu 1$ of enzyme solution was withdrawn at various time intervals and assayed for PDHC activity as described above.

For the PLP inactivation and taurine re-activation experiments, the enzyme solutions were incubated at $30^{\circ} \mathrm{C}$ with appropriate amount of effector for the desired duration as indicated in legends to Figs. 1-4.

The initial rate of the dihydrolipoyl dehydrogenase in PDHC was measured by following a decrease in absorbance at $340 \mathrm{~nm}$ due to the oxidation of NADH to NAD by lipoamide, according to the following equation:

Lipoamide $+\mathrm{NADH}+\mathrm{H}^{+}=$

dihydrolipoamide + NAD

The assay solution $(1.0 \mathrm{ml})$ contained $0.1 \mathrm{~m}$ mole sodium phosphate, $\mathrm{pH} 7.5,0.5 \mu$ mole $\mathrm{MgCl}_{2}, 0.1$ $\mu$ mole NADH, $0.5 \mu$ mole lipoamide and $1 \%(\mathrm{v} / \mathrm{v})$ ethanol. Dihydrolipoyl dehydrogenase activity was measured at $30^{\circ} \mathrm{C}$. Immediately before the kinetic experiments, the stock enzyme solution (1-2 ml) was passed through a column of Sephadex G-25 M (40 x $2 \mathrm{~cm})$ which has been pre-equilibrated with $0.1 \mathrm{M}$ sodium phosphate buffer, $\mathrm{pH} 7.5$, containing $0.5 \mathrm{mM} \mathrm{MgCl}$. Fractions of $3 \mathrm{ml}$ were collected by means of an LKB fraction collector. This chromatographic procedure was necessary to remove traces of DTT which could interfere with the assay of dihydrolipoyl dehydrogenase. 


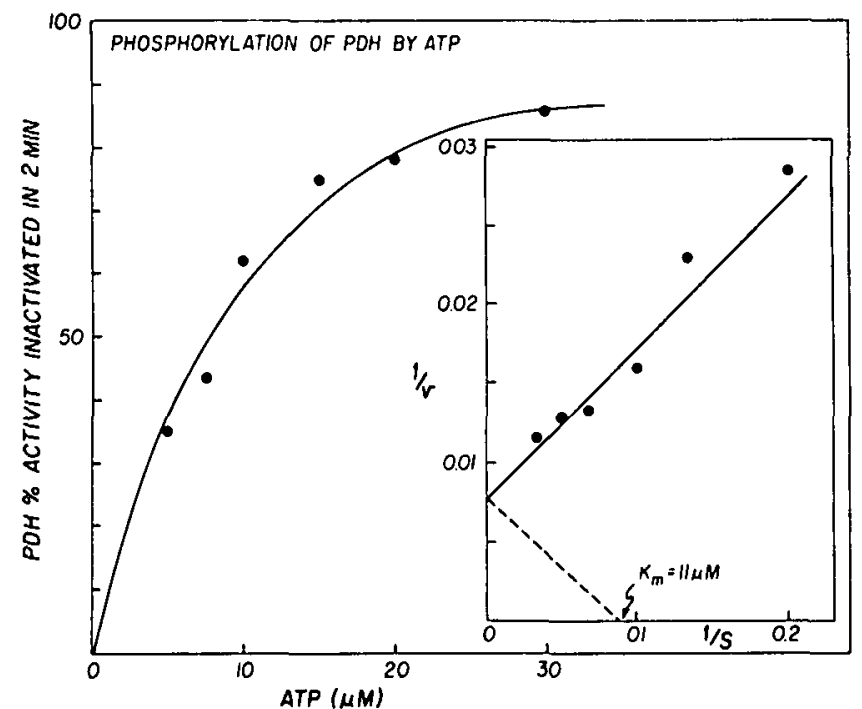

Figure 1-Phosphorylation of PDHC by A TP. The primary plot shows the percent PDHC inactivated in $2 \mathrm{~min}$ after the addition of various concentrations of ATP. The insert is a double reciprocal plot of the data from primary plot. The $\mathrm{Km}$ is calculated to be $11 \mu \mathrm{M}$.

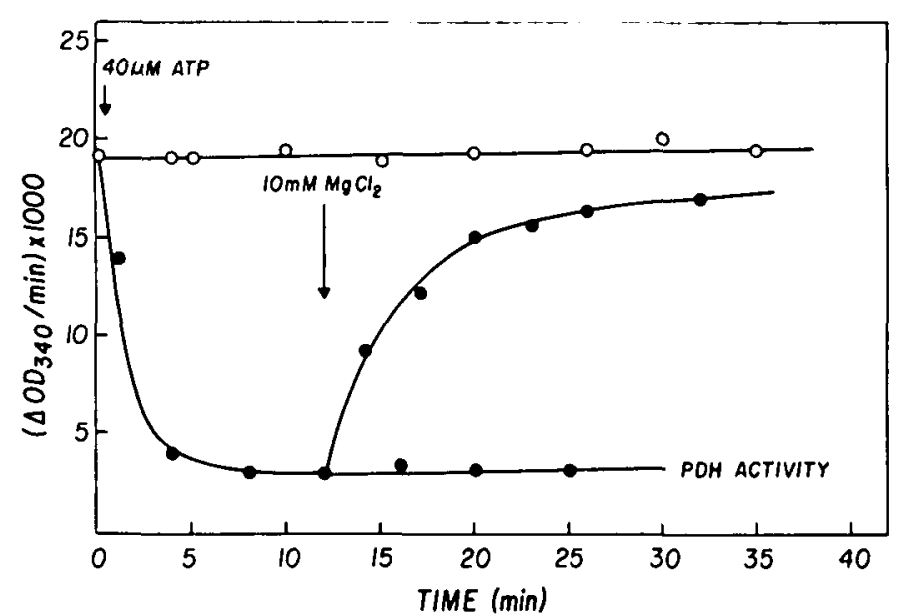

Figure 2-Reactivation of ATP-inactivated PDHC by $10 \mathrm{mM}$ $\mathrm{MgCl}$. Open circles are PDHC activities in the absence of ATP. Closed circles are PDHC inactivated by $40 \mu \mathrm{M}$ ATP and reactivated by $10 \mathrm{mM} \mathrm{MgCl} 212 \mathrm{~min}$ after addition of ATP.

\section{Protein determination}

Proteins were determined by the method of Lowry et al. (1951) using bovine serum albumin as the standard.

\section{RESULTS AND DISCUSSION}

PDHC obtained from rat brain was rapidly inactivated by micromolar quantities of ATP (Fig. 1). The extent of inactivation depends on the concentration of ATP and follows saturable hyperbolic kinetics. The double reciprocal plot of the rate of inactivation against ATP concentration was linear (insert in Fig. 1). This result indicates that the phosphorylation of PDHC by ATP is an enzyme-catalyzed reaction. The phosphorylation of PDHC can only be brought about by ATP, other nucleotide triphosphates being ineffective. Neither cyclic-AMP, AMP, ADP, phosphoenolpyruvate nor glucose-6-phosphate could phosphorylate the enzyme. The phosphorylation requires the presence of low concentration of $\mathrm{Mg}^{2+}(1 \mathrm{mM})$. The $\mathrm{Km}$ for ATP is $11 \mu \mathrm{M}$, which is very similar to the $\mathrm{Km}$ of pig brain and bovine kidney, or heart PDHC, being $8 \mu \mathrm{M}$ and $20 \mu \mathrm{M}$ respectively (Siess et al., 1971; Hucho et al., 1972).
ATP-inactivated PDHC can be reactivated in the presence of high concentration of $\mathrm{MgCl}_{2}(10 \mathrm{mM})$. Fig. 2 shows that when rat brain PDHC was incubated in the presence of $40 \mathrm{mM} \mathrm{ATP}$, its activity rapidly decreased and residual activity persisted after $10 \mathrm{~min}$ incubation at $30^{\circ} \mathrm{C}$. However, when $10 \mathrm{mM}$ of $\mathrm{MgCl}_{2}$ was added at $12 \mathrm{~min}$ after ATP addition, it restored the activity of PDHC to almost its original activity within $20 \mathrm{~min}$ after $\mathrm{MgCl}_{2}$ addition.

The cyclic inactivation by ATP and reactivation by high magnesium ion indicates that rat brain PDHC is also subject to metabolic control by phosphorylation and dephosphorylation, a fact which has been amply demonstrated in other mammalian PDHC (Linn et al., 1969a; Linn et al.,

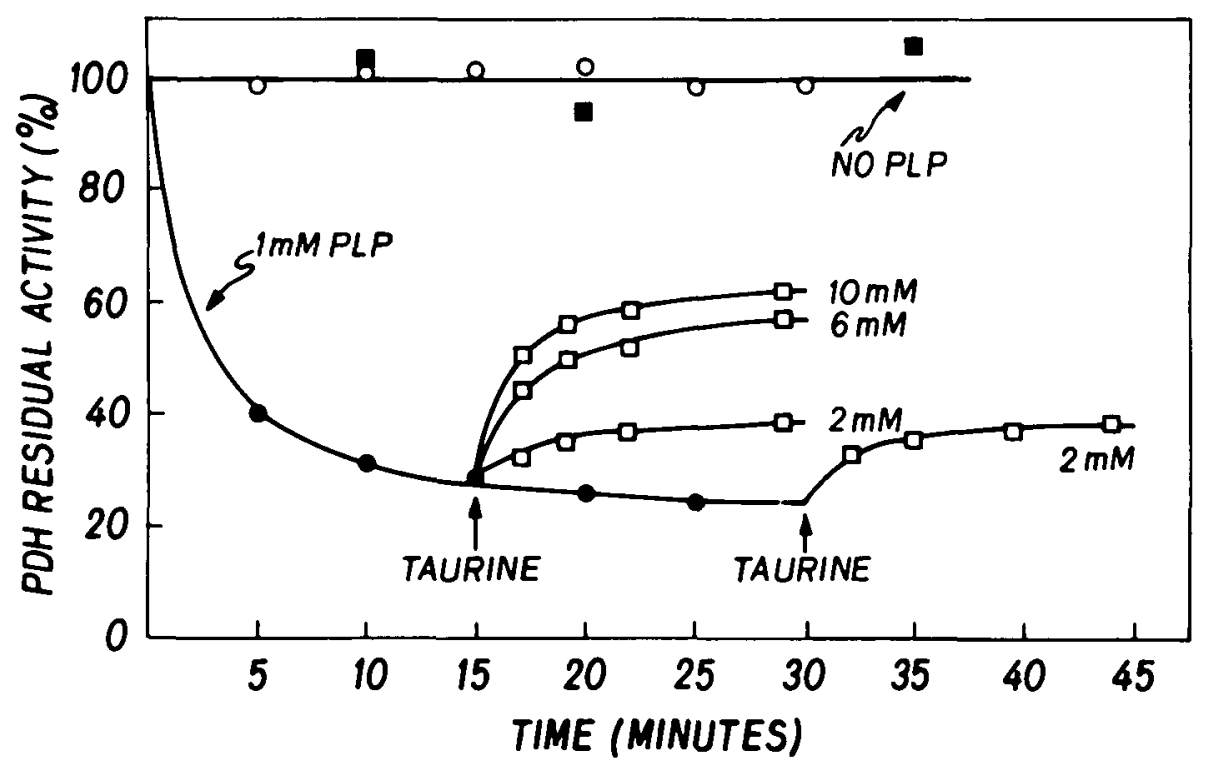

Figure 3-Inactivation of PDHC by pyridoxal phosphate (PLP) and reactivation of PLP-inactivated PDHC by taurine. 


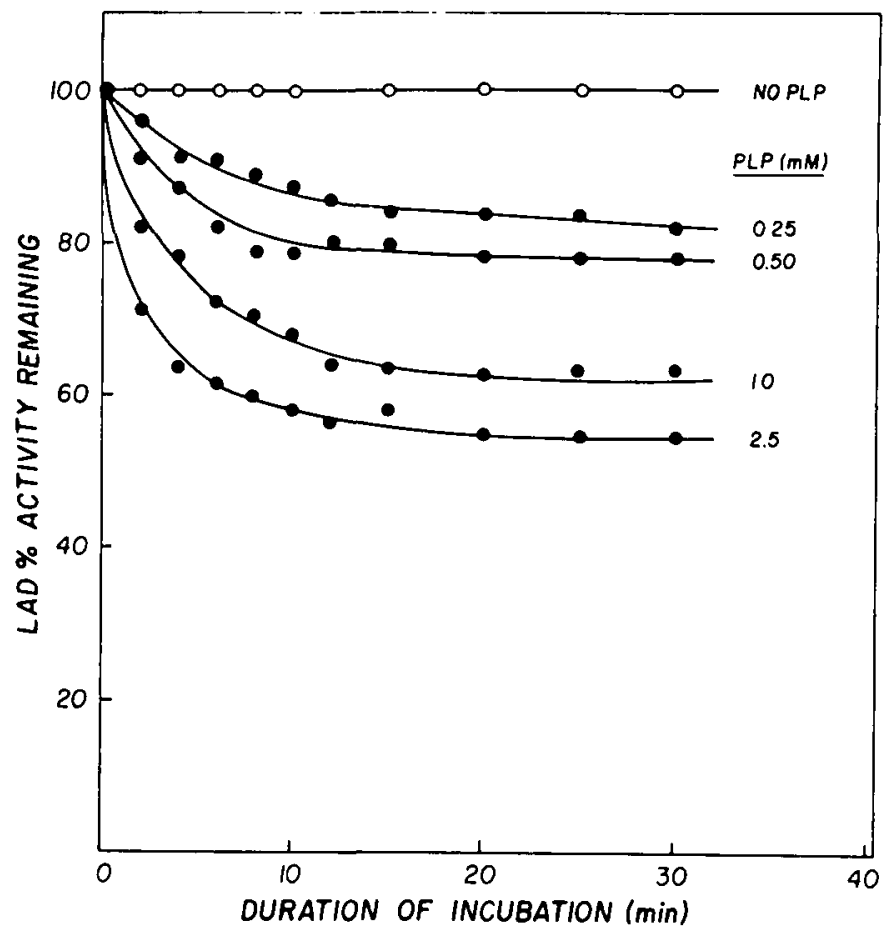

Figure 4-Inactivation of dihydrolipoyl dehydrogenase (LAD) component of PDHC by pyridoxal phosphate.

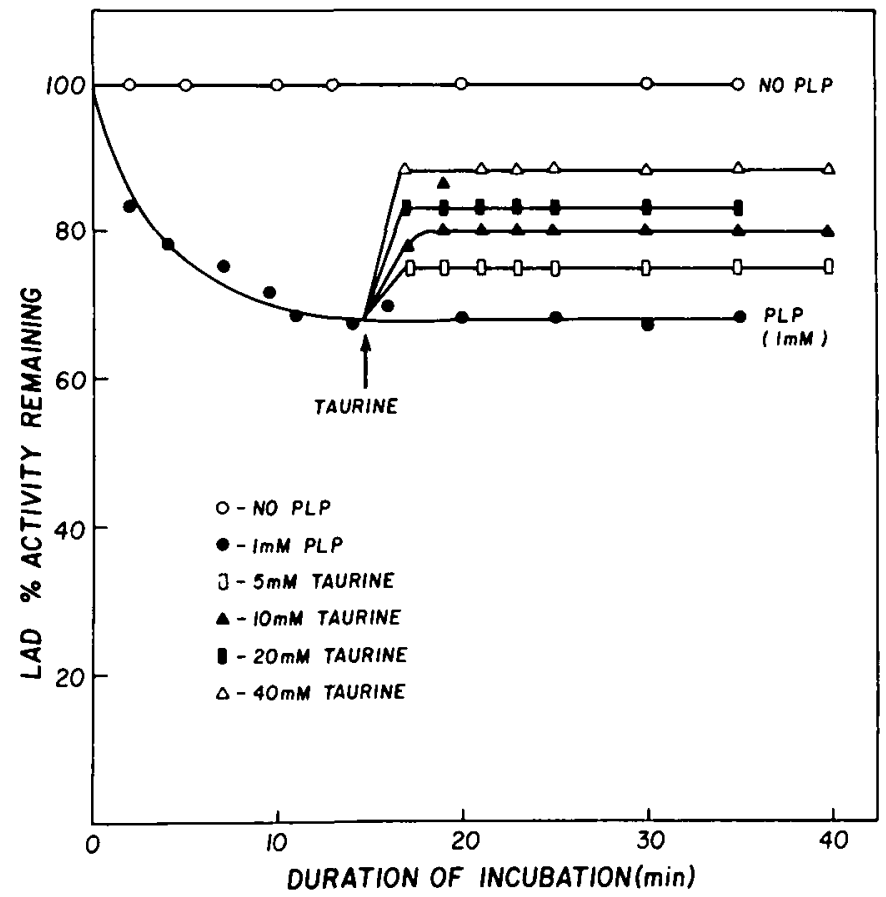

Figure 6-Inactivation of dihydrolipoyl dehydrogenase (LAD) by pyridoxal phosphate (PLP) and reactivation of PLP. inactivated $\mathrm{LAD}$ by taurine.

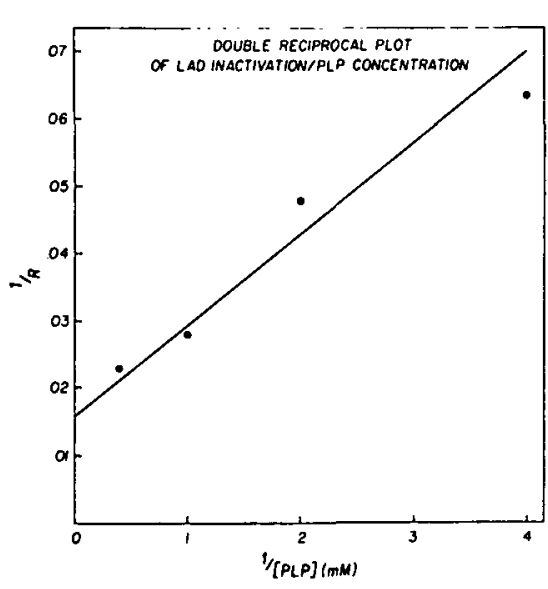

Figure 5-Double reciprocal plot of the data presented in Fig. 4.

1969b; Wieland and Siess, 1970; Siess et al., 1971; Linn et al., 1972; Hucho et al., 1972; Hucho, 1974; Stanbie, 1976; Roche and Cate, 1977). The interconversion of brain PDHC by phosphorylation and dephosphorylation depends on the adenylate energy charge of the brain. Thus, factors that alter the concentrations of adenylate nucleotides can change the activity of PDHC without changing the amount of PDHC (Jope and Blass, 1976). Hypoxia, ischemia and barbiturate anesthesia have been shown to in- fluence the interconversion of guinea pig brain pyruvate dehydrogenase (Ksiezak, 1976).

Izumi et al. (1978) have recently demonstrated that rat brain PDHC is rapidly inactivated by pyridoxal phosphate (PLP) and can be reactivated by the addition of taurine. (Fig. 3). In an attempt to locate the site of action of PLP on PDHC, we have studied the effect of PLP on the activity of dihydrolipoyl dehydrogenase (lipoamide dehydrogenase, LAD), the third enzyme of the PDH complex.

Fig. 4 shows that PLP inactivates LAD of PDHC. The extent of PLP inactivation depends on the PLP concentration in a hyperbolic manner. A double reciprocal plot of the percent $\mathrm{PDHC}$ inactivated against the PLP concentration gave a linear relationship (Fig. 5). This indicates that PLP initially binds to LAD and that this is follwed by the formation of an inactive LAD - PLP complex, most likely via a Schiff base linkage. The dissociation constant of LAD PLP base complex, estimated from Fig. 5 , is $0.9 \mathrm{mM}$.

The reversible formation of a Schiff base is further supported by that fact that taurine, an amino acid, was able to counteract the PLP inactivation of PDHC (Fig. 6) and that the extent of reactivation increased with increasing concentrations of taurine. The results presented in Fig. 3-4 clearly indicate involvement of LAD in the previously reported PLP induced inactivation of PDHC (Izumi et al., 1978). However, these results do not eliminate the possible participations of $E_{1}$ and/or $E_{2}$ in the PLP inactivation of PDHC. Work is now in progress to delineate the possible involvement of the $E_{1}$ and $E_{2}$ components in the action of PLP on PDHC.

The fact that the activity of brain PDHC can be controlled by varying concentrations of PLP, and that this regulation can be modulated by the amino acid taurine, may have some bearing on the physiopathology of symptoms in Friedreich's ątaxia.

\section{ACKNOWLEDGMENTS}

The studies reported in this paper were supported in part by Grants from La Fondation Jeanne Mance de l'Hôtel-Dieu de Montréal, l'Association Canadienne de l'Ataxie de Friedreich and the Medical Research Council of Canada (MT-4938). The authors would like to thank Miss Marie Charbonneau for technical assistance and Miss Suzanne Gariépy for typing the manuscript. 


\section{REFERENCES}

BARBEAU, A., BUTTERWORTH, R. F., NGO, T., BRETON, G., MELANÇON, S., SHAPCOTT, D., GEOFFROY, G. and LEMIEUX, B. (1976). Pyruvate metabolism in Friedreich's ataxia. Can. J. Neurol. Sci., 3, 379-388.

BLASS, J. P., KARK, R. A. P. and MENON, N. K. (1976). Low activities of the pyruvate and oxoglutarate dehydrogenase complexes in five patients with Friedreich's ataxia. New Engl. J. Med., Med., 295, 62-67.

BLASS, J. P. and LEWIS, C. A. (1973). Kinetic properties of the partially purified pyruvate dehydrogenase complex of ox brain. Biochem. J., 131, 31-37.

DENTON, R. M., RANDLE, P. J., BRIDGES, B. J., COOPER, R. H., KERBEY, A. L., PASK, H. T., SEVERSON, D. L., STANBIE, D. and WHITEHOUSE, S. (1975). Regulation of mammalian pyruvate dehydrogenase. Mol. Cell. Biochem., 9, 27-53.

HUCHO, F. (1974). Regulation of the mammalian pyruvate dehydrogenase multienzyme complex by $\mathrm{Mg}^{2}$, and the adenine nucleotide pool. Eur. J. Biochem., 46, 499-505.

HUCHO, F. (1975). The pyruvate dehydrogenase multienzyme complex. Angew, Chem. Internat. Edit., 14, 591-601.

HUCHO, F., RANDALL, D. D., ROCHE, T. E., BURGETT, M. W., PELLEY, J. W. and REED, R. J. (1972). $\alpha$-Keto acid dehydrogenase complexes XVII. Kinetic and regulatory properties of pyruvate dehyd- rogenase kinase and pyruvate dehydrogenase phosphatase from bovine kidney and heart. Arch, Biochem. Biophys., 151. 328-340.

IZUMI, K., NGO, T. T. and BARBEAU, A. (1978). Metabolic modulation by taurine in central nervous system. In: Taurine in Neurological Disorders. A. Barbeau and R. J. Huxtable, eds., Raven Press, New York, in press.

JOPE, R. and BLASS, J. P. (1976). The regulation of pyruvate dehydrogenase in brain in vivo. J. Neurochem., 26, 709-714.

KSIEZAK, H. (1976). Effect of hypoxia, ischemia and barbiturate anesthesia on interconversion of pyruvate dehydrogenase in guinea pig brain. FEBS Letters, 63, 149-153.

LINN, T. C., PELley, J. W., PETTIT, F. H., HUCHO, F., RANDALL, D. D. and REED, L. J. (1972). $\alpha$-Keto acid dehydrogenase complexes $X V$. Purification and properties of the component enzymes of the pyruvate dehydrogenase complexes from bovine kideny and heart. Arch. Biochem. Biophys., 148, 327-342.

LINN, T. C., PETTIT, F. H., HUCHO, F. and REED, L. J. (1969b), $\alpha$-Keto acid dehydrogenase complexes XI. Comparative studies of regulatory properties of the pyruvate dehydrogenase complexes from kidney, heart and liver mitochondria. Proc. Nat. Acad. Sci. U.S.A., 64, 227-234.

LINN, T. C., PETTIT, F. H. and REED, L. J. (1969a). $\alpha$-Keto acid dehydrogenase complexes X. Regulation of the activity of the pyruvate dehydrogenase complex from beef kidney mitochondria by phosphorylation and dephosphorylation. Proc. Nat. Acad. Sci. U.S.A., 62, 234-241.

LOWRY, O. H., ROSEBROUGH, N. J., FARR, A. L. and RANDALL, R. J. (1951). Protein measurement with the folin phenol reagent. J. Biol. Chem. 193, 265-275.

NGO, T. T. and BARBEAU, A. (1978). Steady state kinetics of rat brain pyruvate dehydrogenase multienzyme complex. J. Neurochem., in press.

REED, L. J. (1974). Multienzyme complexes. Accounts of Chem. Res., 7, 40-46.

ROCHE, T. E. and CATE, R. L. (1977). Purification of porcine liver pyruvate dehydrogenase complex and characterization of its catalytic and regulatory properties. Arch. Biochem. Biophys., 183, 664-677.

SIESS, E., WITTMANN, J, and WIELAND, O. (1971). Interconversion and kinetic properties of pyruvate dehydrogenase from brain. Hoppe-Seyler's $Z$. Physiol. Chem., 352, 447-452.

STANBIE, D. (1976). Regulation of the human pyruvate dehydrogenase complex. Clin. Sci. Mol. Med., 51, 445-452.

TSAI, C. S. BURGETT, M. W. and REED, R. J. (1973). $\alpha$-Keto acid dehydrogenase complexes XX. A kinetic study of the pyruvate dehydrogenase complex from bovine kidney. J. Biol. Chem., 248, 8348-8352.

WIELAND, O. and SIESS, E. (1970). Interconversion of phospho- and dephosphoforms of pig heart pyruvate dehydrogenase. Proc. Nat. Acad. Sci. U.S.A., 65, 947-954. 